\title{
Implante Strong SW Plus associado à reconstrução tecidual imediata em área estética
}

\author{
Maiolino Thomaz Fonseca OLIVEIRA ${ }^{1}$; Bruna Neves da SILVA2; \\ Jaime Rodrigues de AGUILAR²; Guilherme José Pimentel Lopes de \\ OLIVEIRA ${ }^{3}$; Bruna GHIRALDINI ${ }^{4}$; Fábio José Barbosa BEZERRA ${ }^{5}$
}

1 - Doutor em Odontologia, área de Cirurgia Bucomaxilofacial e Implantodontia pela Universidade Federal de Uberlândia (UFU), Uberlândia-MG, Brasil; 2 - Especialista em Implantodontia pelo Instituto de Medicina, Estudos e Desenvolvimento (IMED) - Montes Claros - MG, Brasil; 3 - Professor Adjunto da disciplina de Periodontia/Implantodontia da Universidade Federal de Uberlândia (UFU), Uberlândia-MG, Brasil; 4 - Doutora em Implantodontia pela Universidade Paulista (UNIP), São Paulo-SP, Brasil; 5- Doutor em Biotecnologia, Universidade Estadual Paulista Julio de Mesquita Filho (UNESP), Botucatu-SP, Brasil.

\section{Resumo}

Esse relato de caso tem como objetivo apresentar a instalação imediata de implantes com macroestrutura híbrida, com tratamento de superfície por adição de nanopartículas de hidroxiapatita na resolução de uma condição clínica de fratura radicular de dente anterior associado a reabsorção óssea na parede vestibular do alvéolo dentário. Paciente procurou atendimento odontológico com queixa de fratura dentária do dente 21 que foi confirmada após exodontia. Foi instalado um implante imediato com macroestrutura híbrida com tratamento de superfície por adição de nanopartículas de hidroxiapatita. Imediatamente após a instalação do implante, foi realizada reconstrução do alvéolo com preenchimento do gap ósseo com enxerto ósseo bovino desproteinizado e reconstrução do tecido mole periimplantar com enxerto de tecido conjuntivo. Após o manejo cirúrgico, realizou-se a confecção de um provisório em carga imediata utilizando o próprio dente da paciente. Foi executada uma segunda cirurgia de enxerto de tecido conjuntivo subepitelial com objetivo de melhorar o padrão morfológico tecidual associado ao implante. Três meses após essa segunda intervenção foi possível verificar uma melhora no padrão periimplantar e a prótese final foi instalada sobre o implante. A técnica de exodontia minimamente invasiva associada a utilização de substituto ósseo e enxerto de tecido conjuntivo subepitelial foram eficazes na manutenção do alvéolo pós-extração associado a instalação imediata de implante com carregamento imediato. Esse tipo de abordagem só é possível de ser executada com previsibilidade caso o implante apresente boas propriedades de macro, micro e nanoestrutura.

PALAVRAS-CHAVE: Implantes dentários; Carga Imediata em Implante Dentário; Estética dentária. 


\section{Introdução}

A busca por protocolos que permitam a instalação imediata de implantes dentários após a exodontia tem sido estimulada na prática clínica diária devido a melhor manutenção dos tecidos do alvéolo dentário ao se aplicar essa técnica ${ }^{1}$. De fato, estudos pré-clínicos e clínicos anteriores tem demonstrado que a instalação imediata de implantes é eficiente na redução da perda óssea da parede vestibular e que esse tipo de abordagem deve ser executado sempre que possível ${ }^{1-4}$. Para que se possa aumentar a possibilidade de sucesso nessa abordagem se faz necessário cuidados em relação à técnica cirúrgica de exodontia que deve ser a mais conservadora possível $^{5,6}$, instalação de implante de forma adequada evitando que o mesmo entre em contato com a parede óssea vestibular ${ }^{7}$, preenchimento do espaço entre o implante e a parede óssea com substitutos ósseos com baixa taxa de remodelação ${ }^{8}$ e indicação de aumento de volume do tecido mole periimplantar por meio de técnicas de enxerto especialmente em pacientes com fenótipo gengival fino ${ }^{5}$.

Para se trabalhar nessa condição localmente crítica de forma previsível, é de extrema importância utilizar implantes que permita uma boa estabilidade primária em uma situação de plano inclinado na parede lingual ou palatina de alvéolos pós-extração com pouca quantidade de osso na porção apical dos implantes $^{7,8}$. Para que isso seja possível, o desenho do corpo e espiras dos implantes dentários pode favorecer a estabilidade primária, tornando possível o carregamento imediato dos implantes ${ }^{9,10}$. Além disso, o tratamento de superfície dos implantes a fim de otimizar o processo de osseointegração acelerando a obtenção da estabilidade secundária dos implantes ${ }^{11}$.

Esse relato de caso tem como objetivo apresentar a instalação imediata de implantes com macrogeometria híbrida (implante cilíndrico cônico), com tratamento de superfície por adição de nanopartículas de hidroxiapatita na resolução de uma condição clínica de fratura radicular de dente anterior associado a reabsorção óssea na parece vestibular do alvéolo dentário. 


\section{Relato de caso clínico}

Paciente do gênero feminino, 27 anos, procurou atendimento odontológico com queixa de fratura dentária. Ao exame clínico, foi observado uma fixação da coroa dentária do 21 aos dentes adjacentes com resina composta (Figura 1A-B). Ao exame radiográfico, foi notadoum sinal sugestivo de fratura radicular (Figura 1C). Após anestesia local e preparo do campo operatório, foi realizada a remoção da resina composta e foi possível identificar a fratura coronária que comprometia a integridade do dente 21 (Figura 1D). Diante a estes achados, a opção terapêutica definida pelo profissional e paciente consistiu em exodontia seguida de implante e reconstrução imediatas dos tecidos.

Foi realizada exodontia minimamente invasiva, evitando-se incisões e descolamento dos tecidos moles, no sentido de evitar que o procedimento cirúrgico causasse alterações alveolares importantes. Após a exodontia, pode-se observar um defeito da parede óssea vestibular e alterações do tecido mole periodontal (Figura 1E). Em seguida, foi realizada a instalação de implante Strong SW Plus (S.I.N Implant System) de 3.5x13mm, de macroestrutura híbrida (implante cilíndrico cônico), com tratamento de superfície por adição de nanopartículas de hidroxiapatita (Figura 1F).

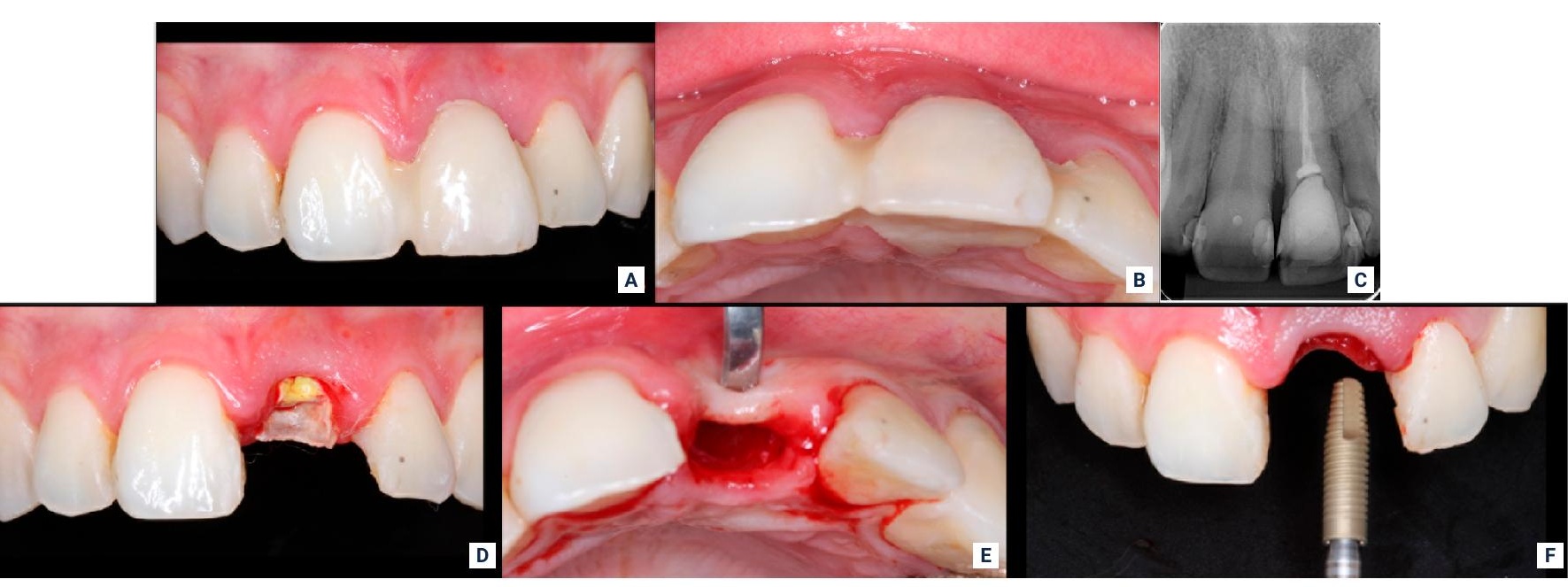

FIGURA 1 - (A-B) Condição clínica inicial onde é possível observar a fixação da coroa dentária do 21 aos dentes adjacentes com resina composta. (C) No exame radiográfico foi notado sinal sugestivo de fratura radicular; (D) Identificação clínica da fratura radicular após a remoção da resina; (E) Após a exodontia pode-se observar um defeito da parede óssea vestibular e também alterações do tecido mole periodontal; (F) Instalação do implante com macroestrutura híbrida e tratamento de superfície com duplo ataque ácido adição de nanopartículas de hidroxiapatita (Strong SW Plus 3.5×13mm, S.I.N Implant System, São Paulo, Brasil). 
Imediatamente após a instalação do implante, foi realizada reconstrução imediata do alvéolo com preenchimento do gap ósseo com enxerto ósseo bovino particulado e também reconstrução do tecido mole periimplantar com enxerto de tecido conjuntivo (Figura 2A-B). Após o manejo cirúrgico, realizou-se a confecção de um provisório em carga imediata utilizando o próprio dente da paciente (Figura 2C-E). Três meses após a instalação do implante, foi realizada moldagem para confecção de prótese definitiva em porcelana e também reembasamento do provisório, além disso, foi possível observar importante melhora do tecido mole periimplantar, porém não o suficiente para um bom perfil de emergência da prótese definitiva (Figura $2 \mathrm{~F})$. Dessa forma, nesse segundo momento foi executada uma segunda cirurgia de enxerto de tecido conjuntivo subepitelial com objetivo de melhorar o padrão morfológico tecidual associado ao implante (Figura 3A-F). 3 meses após essa segunda intervenção foi possível verificar uma melhora no padrão periimplantar (Figura 3G-H) e a prótese final foi instalada sobre o implante (Figura 3I).

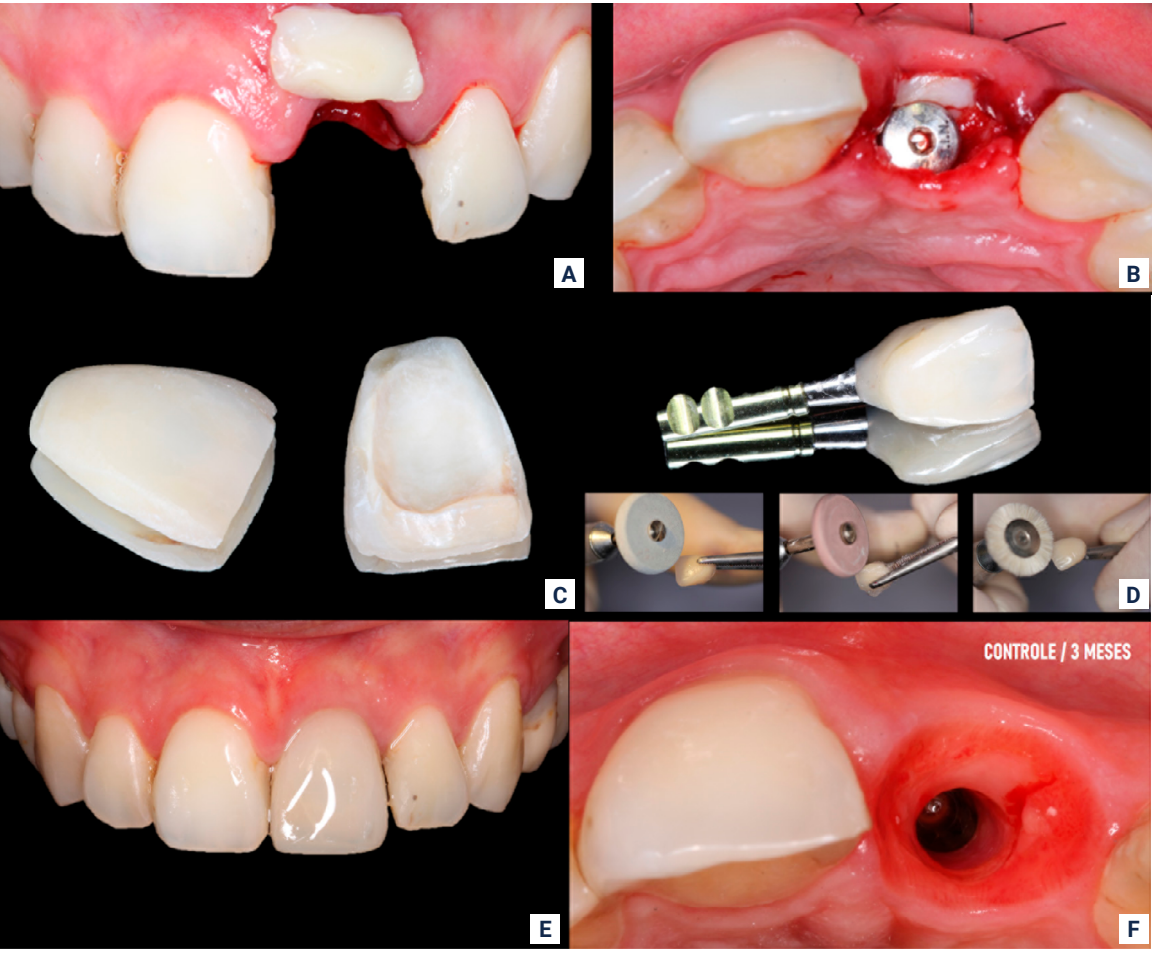

FIGURA 2 - (A-B) Imediatamente após a instalação do implante, foi realizada reconstrução imediata do alvéolo com preenchimento do gap ósseo com enxerto ósseo bovino particulado e também reconstrução do tecido mole periimplantar com enxerto de tecido conjuntivo subepitelial; (C-E) Após o manejo cirúrgico, realizou-se a confecção de um provisório em carga imediata utilizando o próprio dente da paciente; (F) Três meses após a instalação do implante, foi possível observar importante melhora do tecido mole periimplantar, porém não o suficiente para um bom perfil de emergência da prótese definitiva. 


\section{Discussão}

Condições locais em regiões anteriores são desafiadoras para a reabilitação em implantodontia, pois as repercussões psicológicas e sociais para perdas de elementos dentários nessa região tem grande impacto na qualidade de vida dos pacientes ${ }^{12}$. Dessa forma, a instalação imediata de implantes com carregamento imediato dos mesmos tem sido proposta para acelerar o procedimento reabilitador definitivo, e que o tempo de espera para a finalização do caso clínico seja o mais confortável e satisfatório possível para o paciente ${ }^{1,4}$. Entretanto, essas condições locais requerem a utilização de implantes que permita boa estabilidade primária em locais com pouca disponibilidade óssea ${ }^{13}$, bem como esses implantes devem apresentar uma superfície com boas propriedades osteocondutoras para que o processo de osseointegração ocorra de forma rápida e previsível mesmo em condições clínicas difíceis ${ }^{14}$.

No caso apresentado, foi verificado que o dente 21 apresentava fratura que estava associada a perda óssea da parede vestibular. Esse tipo de condição promove alterações estéticas importantes, pois a extração dentária pode vir acompanhada de extensiva reabsorção óssea e formação de defeito ósseo crítico que poderá requerer a
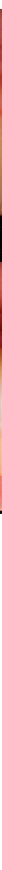

FIGURA $3 \cdot$ (A-B) Execução do segundo procedimento cirúrgico onde foi executada incisão e descolamento do tecido mucoso periimplantar; (C) remoção do enxerto de tecido conjuntivo subepitelial do palato do paciente; (D-F) Acomodação do enxerto no leito cirúrgico receptor; (G-H) Comparação do perfil de emergência após a primeira e a segunda cirurgia; (I) Prótese final instalada. 
necessidade de regeneração óssea guiada para posteriormente se instalar o implante dentário ${ }^{1,15}$. Esse tipo de conduta, apesar de ser previsível na resolução do problema, poderia atrasar o tratamento reabilitador definitivo e aumentar os gastos e complexidade do mesmo ${ }^{15}$. Devido a isso, foi indicada a instalação imediata dos implantes, com utilização de enxerto de tecido conjuntivo subepitelial e uso de osso bovino desproteinizado, e todas essas ações permitiram a manutenção e um bom perfil tecidual da mucosa periimplantar na face vestibular do implante que foi instalado ${ }^{16}$. Vale ressaltar que a segunda abordagem cirúrgica para aumentar volume de tecido mucoso periimplantar foi indicado devido à observação de que o perfil desse tecido ainda poderia ser melhorado, fato que não deve ser descartado em sítios com grandes reabsorções ósseas, tal como no caso exposto, pois os enxertos de tecido conjuntivo subepitelial possuem a capacidade de ganho de espessura que pode variar de 2.41 até $3.10 \mathrm{~mm}$ em cada intervenção ${ }^{17}$, e defeitos maiores pode requerer essa segunda abordagem.

Outro fator técnico importante a ser levado em consideração no sucesso da técnica exposta nesse relato foi a aplicação de uma manobra de exodontia minimamente invasiva onde não houve rebatimento de retalho durante o procedimento cirúrgico o que pode ter influenciado no bom padrão morfológico resultante da intervenção desse caso. A exodontia executada dessa forma beneficia a manutenção da arquitetura tecidual, pois minimiza a remodelação tecidual e mantém o periósteo aderido as cristas ósseas protegendo e nutrindo o tecido duro e otimizando o reparo pós-extração ${ }^{18}$. Outro importante fator que pode explicar o sucesso na reabilitação do caso exposto foi a utilização de um implante com macroestrutura híbrida que permite o travamento desse tipo de implantes em osso com quantidade e qualidade reduzida ${ }^{10}$. Além disso, a superfície instalada apresentava modificações por duplo ataque ácido associado a nanopartículas de hidroxiapatita que estimula a diferenciação e atividade de osteoblastos $^{19,20}$. Essas características em conjunto justificam a boa resposta do implante utilizado em manter-se estável no 
momento de sua instalação na porção apical do alvéolo devido a sua macroestrutura, e em alcançar a osseointegração adequada mesmo nessa condição desafiadora devido as boas propriedades de sua superfície.

Por fim, no caso descrito optou-se pela utilização de um implante estreito com plataforma do tipo cone morse para ser instalado no alvéolo pós-extração. A vantagem de se utilizar o implante de diâmetro estreito em alvéolos frescos da região anterior da maxila está em criar um gap maior entre o implante e a parede óssea vestibular, tendo a oportunidade de preencher o gap com substitutos ósseos, aumentando então a parede de proteção do implante ${ }^{1}$. Implantes com maiores diâmetros instalados em alvéolos de menor diâmetro anteroposterior pode reduzir o gap entre a parede do alvéolo e do implante o que pode promover maiores reabsorções do topo da crista óssea vestibular ${ }^{1,5,6}$.

Além disso, o uso de implante com plataforma do tipo cone morse é responsável pala manutenção longitudinal do módulo da crista e essa conexão deve ser preferível na escolha do implante a ser instalado em condições clínicas semelhantes ao caso clínico relatado nesse estudo ${ }^{21}$.

Dessa forma, pode-se concluir que a técnica de exodontia minimamente invasiva associada a utilização de substituto ósseo e enxerto de tecido conjuntivo subepitelial foram eficazes na manutenção do alvéolo pós-extração associado a instalação imediata de implante com carregamento imediato. Esse tipo de abordagem só foi possível, pois a macroestrutura do implante permitiu uma boa estabilidade primária mesmo em uma condição complexa como em um alvéolo pós-extração enquanto que sua microestrutura permitiu que o processo de osseointegração ocorresse de forma satisfatória, sem ocorrência de efeitos adversos e reduzindo o risco cirúrgico por permitir a redução da quantidade de abordagens cirúrgicas em detrimento ao protocolo de instalação de implantes em alvéolos previamente cicatrizados. 


\section{Referências}

1 - Chappuis V, Araújo MG, Buser D. Clinical relevance of dimensional bone and soft tissue alterations post-extraction in esthetic sites. Periodontol 2000. 2017; 73(1): 73-83.

2- Araújo MG, Sukekava F, Wennström JL, Lindhe J. Ridge alterations following implant placement in fresh extraction sockets: an experimental study in the dog. J Clin Periodontol. 2005; 32(6): 645-652.

3 - Deng F, Zhang H, Zhang H, Shao H, He Q, Zhang P. A Comparison of clinical outcomes for implants placed in fresh extraction sockets versus healed sites in periodontally compromised patients: a 1-year follow-up report. Int J Oral Maxillofac Implants. 2010; 25(5): 1036-1040.

4 - Mangano FG, Mangano C, Ricci M, Sammons RL, Shibli JA, Piattelli A. Esthetic evaluation of single-tooth morse taper connection implants placed in fresh extraction sockets or healed sites. J Oral Implantol. 2013; 39(2): 172-181.

5 - Testori T, Weinstein T, Scutellà F, Wang HL, Zucchelli G. Implant placement in the esthetic area: criteria for positioning single and multiple implants. Periodontol 2000. 2018; 77(1): 176-196.

6- Zucchelli G, Sharma P, Mounssif I. Esthetics in periodontics and implantology. Periodontol 2000. 2018; 77(1): 7-18.

7 - Grassi FR, Grassi R, Rapone B, Alemanno G, Balena A, Kalemaj Z. Dimensional changes of buccal bone plate in immediate implants inserted through open flap, open flap and bone grafting and flapless techniques: A cone-beam computed tomography randomized controlled clinical trial. Clin Oral Implants Res. 2019; 30(12): 1155-1164.

8 - Bittner N, Planzos L, Volchonok A, Tarnow D, Schulze-Späte U. Evaluation of Horizontal and Vertical Buccal Ridge Dimensional Changes After Immediate Implant Placement and Immediate Temporization With and Without Bone Augmentation Procedures: Short-Term, 1-Year Results. A Randomized Controlled Clinical Trial. Int J Periodontics Restorative Dent. 2020; 40(1): 83-93.

9 - Campos FE, Jimbo R, Bonfante EA, Barbosa DZ, Oliveira MT, Janal MN, et al. Are insertion torque and early osseointegration proportional? A histologic evaluation. Clin Oral Implants Res. 2015; 26(11): 1256-1260.

10 - Coelho PG, Jimbo R, Tovar N, Bonfante EA. Osseointegration: hierarchical designing encompassing the macrometer, micrometer, and nanometer length scales. Dent Mater. 2015; 31(1): 37-52.

11 - Jimbo R, Coelho PG, Bryington M, Baldassarri M, Tovar N, Currie F, et al. Nano hydroxyapatite-coated implants improve bone nanomechanical properties. J Dent Res. 2012; 91(12): 1172-1177.

12 - Haag DG, Peres KG, Balasubramanian M, Brennan DS. Oral Conditions and Health-Related Quality of Life: A Systematic Review. J Dent Res. 2017; 96(8): 864-874. 
13 - Valente ML, de Castro DT, Shimano AC, Lepri CP, dos Reis AC. Analysis of the influence of implant shape on primary stability using the correlation of multiple methods. Clin Oral Investig. 2015; 19(8):1861-1866.

14 - Jimbo R, Sotres J, Johansson C, Breding K, Currie F, Wennerberg A. The biological response to three different nanostructures applied on smooth implant surfaces. Clin Oral Implants Res. 2012; 23(6): 706-712.

15 - 15- Schropp L, Kostopoulos L, Wenzel A, Isidor F. Clinical and radiographic performance of delayed-immediate single-tooth implant placement associated with peri-implant bone defects. A 2-year prospective, controlled, randomized follow-up report. J Clin Periodontol. 2005; 32(5): 480-487.

16 - Atieh MA, Alsabeeha NH, Payne AG, Duncan W, Faggion CM, Esposito M. Interventions for replacing missing teeth: alveolar ridge preservation techniques for dental implant site development. Cochrane Database Syst Rev. 2015; 28(5): CD010176.

17 - 17- Bassetti RG, Stähli A, Bassetti MA, Sculean A. Soft tissue augmentation procedures at second-stage surgery: a systematic review. Clin Oral Investig. 2016; 20(7): 1369-1387.

18 - Hong B, Bulsara Y, Gorecki P, Dietrich T. Minimally invasive vertical versus conventional tooth extraction: An interrupted time series study. J Am Dent Assoc. 2018; 149(8): 688-695.

19 - Bezerra F, Ferreira MR, Fontes GN, Fernandes CJC, Andia DC, Cruz NC, et al. Nano hydroxyapatite-blasted titanium surface affects preosteoblast morphology by modulating critical intracellular pathways. Biotechnol Bioeng. 2017; 114(8): 1888-1898.

20 - Martinez EF, Ishikawa GJ, Lemos AB, Barbosa Bezerra FJ, Sperandio M, Napimoga MH. Evaluation of a Titanium Surface Treated with Hydroxyapatite Nanocrystals on Osteoblastic Cell Behavior: An In Vitro Study. Int J Oral Maxillofac Implants. 2018; 33(3): 597-602.

21 - Pessoa RS, Sousa RM, Pereira LM, Neves FD, Bezerra FJ, Jaecques SV, et al. Bone Remodeling Around Implants with External Hexagon and Morse-Taper Connections: A Randomized, Controlled, Split-Mouth, Clinical Trial. Clin Implant Dent Relat Res. 2017; 19(1): 97-110. 


\title{
Strong SW Plus implant associated with immediate tissue reconstruction in the aesthetic área
}

\begin{abstract}
This case report aims to present the immediate installation of implants with hybrid macrostructure, with surface treatment by the addition of hydroxyapatite nanoparticles in the resolution of a clinical condition of root fracture in anterior tooth associated with bone resorption in the buccal wall of the dental alveolus. The patient sought dental care complaining of tooth fracture of tooth 21, which was confirmed after tooth extraction. An immediate implant with hybrid macrostructure with surface treatment by the addition of hydroxyapatite nanoparticles was installed. After the implant placement, an immediate reconstruction of the socket was performed by filling the bone gap with deproteinized bovine bone graft and reconstruction of the peri-implant soft tissue with connective tissue graft. After surgical management, an immediate provisional loading was made using the patient's own tooth. A second subepithelial connective tissue graft surgery was performed in order to improve the tissue morphological pattern associated with the implant. Three months after this second intervention, it was possible to see an improvement in the peri-implant pattern and the definitive prosthesis was installed on the implant. The minimally invasive extraction technique associated with the use of bone substitute and subepithelial connective tissue graft were effective in maintaining the post-extraction socket associated with immediate implant installation with immediate loading. This type of approach is only possible to be performed with predictability if the implant has good macro, micro and nanostructure properties.
\end{abstract}

KEYWORDS: Dental Implants; Immediate Dental Implant Loading;

Esthetics, Dental.

\section{Como citar este artigo}

Oliveira MTF, Silva BN, Aguilar JR, Oliveira GJPL, Ghiraldini B, Bezerra FJB. Implante Strong SW

Plus associado à reconstrução tecidual imediata em área estética. Rev Odontol Bras Central

2021; 30(89): 222-231. DOI: 10.36065/robrac.v30i89.1520 